\title{
Conditioning of tentacle lowering in the snail (Helix aspersa): Acquisition, latent inhibition, overshadowing, second-order conditioning, and sensory preconditioning
}

\author{
IGNACIO LOY, VANESA FERNÁNDEZ, and FÉLIX ACEBES \\ Universidad de Oviedo, Oviedo, Spain
}

\begin{abstract}
In a series of related experiments, we studied associative phenomena in snails (Helix aspersa), using the conditioning procedure of tentacle lowering. Experiments $1 \mathrm{~A}$ and $1 \mathrm{~B}$ demonstrated a basic conditioning effect in which the pairing of an odor (apple) as the conditioned stimulus (CS) with the opportunity to feed on carrot as the unconditioned stimulus (US) made snails exhibit increased levels of tentacle lowering in the presence of the CS. Experiments 2 and 3 showed that the magnitude of the conditioning was reduced when snails were exposed to the CS prior to the conditioning trial (a latent inhibition effect). Experiment 4 examined the effects produced by pairing a compound CS (apple-pear) with food presentations and demonstrated the existence of an overshadowing effect between the two odors. Experiment 5 revealed that pairing one CS with another previously conditioned stimulus increased tentacle lowering to the new CS (a second-order conditioning effect). Finally, Experiment 6 showed that pairing two odors prior to conditioning of one of them promoted an increase in tentacle lowering in response to the other (a sensory preconditioning effect). The results are discussed in terms of an associative analysis of conditioning and its implications for the study of cognition in invertebrates.
\end{abstract}

Studies of conditioning in invertebrates are important for at least two reasons. First, conditioning speed provides an operational definition of learning ability and thus allows for the comparison among species necessary for a comparative view of cognition (Wasserman, 1984). Second, conditioning in invertebrates has provided important information relevant to the understanding of the physiological bases of learning and memory (Burrell \& Sahley, 2001; see also Carlson, 1994). Unfortunately, the methods and procedures used in neuroscience and brain research are often specifically tailored to particular research interests (e.g., Carretta, Hervé-Minvielle, Bajo, Villa, \& Rouiller, 1999; Metz \& Whishaw, 2002) and often fail to make use of the enormous cumulative experience generated by previous research on associative learning.

\footnotetext{
This research was supported by "Ayudas para proyectos de investigación de grupos emergentes" Universidad de Oviedo (MB-02-506-1, MB-03-506-1, and MB-04-506). Some of the data of Experiment 6 were collected by Gala Gash. We thank Francisco Valle, Luis G. Laplaza, and Félix Junco for their helpful review of early drafts of this manuscript. André Castillón improved our English considerably. Mark Ungless provided important advice regarding many experimental details. Sadaiko Nakajima supplied relevant references. Two anonymous reviewers made relevant theoretical and methodological points that improved the discussion and the general structure of the article. Karen Hollis showed an enthusiastic interest for the work, in spite of the initial version she saw. And last but not least, we are deeply grateful for Geoffrey Hall's positive reinforcement because he did much more than review the manuscript. Correspondence concerning this article should be addressed to I. Loy, Departamento de Psicología, Plaza Feijoo, 33003 Oviedo, Spain (e-mail: iloy@uniovi.es).
}

Sahley, Gelperin, and Rudy (1981) investigated the role of associative learning in the regulation of food selection behavior in Limax maximus. These authors employed an aversive conditioning procedure, in which an odor was used as the conditioned stimulus (CS) and a bitter taste (quinidine sulfate) was used as the unconditioned stimulus (US). They found evidence for a range of standard associative phenomena such as second-order conditioning, blocking, and a US-preexposure effect. The aim of the present experiments was to continue this type of analysis, using an appetitive procedure functionally equivalent to those often used in learning research with vertebrates, such as magazine approach in rats, or salivation in dogs.

We started by replicating Ungless's food attraction conditioning (Ungless, 1998) and then extended the procedure in order to obtain evidence of a range of associative phenomena. Ungless used an appetitive conditioning procedure in which the CS was the odor of a fruit (apple) and the US was provided by the consumption of a piece of carrot. As a conditioned response (CR), he used the lowering of the posterior tentacle in the presence of the CS. With this simple procedure, Ungless showed conditioning of the tentacle lowering response and explained this finding as an instance of Pavlovian conditioning related to feeding (snails exhibit high levels of tentacle lowering when they feed).

In Experiments 1A and 1B, we investigated the acquisition of a conditioned response to the odor of apple. In Experiments 2 and 3, we looked for a latent inhibition effect in this training procedure. In Experiment 4, we in- 
vestigated the effects produced by presenting the CS in compound with another odor, to test whether the presence of this other odor would overshadow the development of a conditioning to the target odor. In Experiment 5, we looked for evidence of a second-order conditioning effect. Finally, Experiment 6 showed that experience of an apple-pear compound prior to conditioning of one of the odors generated an increase of tentacle lowering in response to the other (a sensory preconditioning effect). In the General Discussion section, we will consider the implications of our findings for research in comparative cognition and for the application of associative theories to the study of the invertebrate "mind."

\section{EXPERIMENT 1A}

Our aim in this experiment was to replicate the conditioning effect previously reported by Ungless (1998). Two different groups were used. The experimental, or paired, group received six pairings of the CS and the US, whereas the control, or unpaired, group received uncorrelated presentations of the same CSs and USs. The CS was the odor of apple and the US was a piece of carrot. Evidence of associative learning would occur if subjects in the paired group showed a greater number of tentacle lowering responses during the presence of the CS than did subjects in the unpaired group. It should be acknowledged, however, that if snails show high levels of spontaneous tentacle lowering prior to conditioning, an explanation in terms of a habituation process could be possible. Animals in the unpaired group might show low levels of conditioned responding because they developed habituation to the apple odor, whereas, for animals in the paired group, this habituation process might be disrupted by the presence of carrot. So, before any conditioning treatment, all the snails were exposed to the CS for $2 \mathrm{~min}$ and their tentacle lowering responses were scored to determine their initial response to that stimulus. If animals showed high levels of tentacle lowering prior to conditioning, an explanation in terms of attenuation of habituation could be viable. On the contrary, if snails showed low rates of response prior to conditioning and higher rates after conditioning, this would disconfirm the attenuation-of-habituation hypothesis.

\footnotetext{
Method

Subjects. The subjects were 12 snails taken from the wild, with a shell diameter of $26 \mathrm{~mm}$ (range, $22-30 \mathrm{~mm}$ ) at the start of the experiment. The snails were individually housed in plastic cages (50 mm long $\times 50 \mathrm{~mm}$ wide $\times 100 \mathrm{~mm}$ high) with air holes and a small amount of water, and situated in a cool dark room $\left(20^{\circ} \pm 2^{\circ} \mathrm{C}\right)$. They were given access to rat food for 2 days and were then deprived of food for 10 days prior to the start of the experiment. During the experiment, the snails ate only during conditioning. Due to the death of 1 snail from each group, the pretest data include 12 subjects and the posttest data include 10 subjects.

Apparatus. A plastic perforated surface $(500 \mathrm{~mm} \times 250 \mathrm{~mm}$; $2.5 \mathrm{~mm}$ diameter holes) was used. It was supported at each corner above the table ( $60 \mathrm{~mm}$ above the surface) to allow a slice of fruit to be placed beneath the plastic surface. The experimental room was maintained at approximately $20^{\circ} \mathrm{C}$ and illuminated with a red light
} $(60 \mathrm{~W})$.
Procedure. After the 10-day deprivation period, the snails were randomly assigned to two equal-sized groups $(n=6)$. The day before conditioning, the level of the tentacle lowering to the CS (apple) was scored in all the animals. Only the snail's left posterior tentacle was observed (to simplify the testing procedure). Following Ungless's procedure (see Ungless, 2001, Figure 2, p. 99), we scored as one response the movement of the tentacle below an imaginary line over the top of the head. The number of responses was recorded for 2 min during stimulus presentation. The following day, animals in the paired group $(n=6)$ were exposed to the apple odor (the CS) while given access to carrot for $10 \mathrm{~min}$ (the US). A slice of apple (approx. $6 \mathrm{~cm}$ in diameter) was placed under the perforated surface in the same way as in the pretest, except for the presence of carrot. Immediately prior to conditioning, the snails were dipped in water and placed on their sides to induce activity. Once the snail had emerged from its shell, it was placed onto the perforated surface. A small piece of food (approx. $1 \mathrm{~cm}^{2}$ ) was immediately placed in front of the snail, which was allowed to eat for $10 \mathrm{~min}$ (the 10 -min period began $5 \mathrm{sec}$ after the presentation of the food, by which time the snail had typically begun eating). After this period of time, the snail was returned to its container. Animals in the unpaired group received trials consisting of $10 \mathrm{~min}$ of exposure to apple odor alone. One hour after odor exposure, the snails in the unpaired group were allowed to eat a piece of carrot for $10 \mathrm{~min}$ on the perforated surface. For both groups, we measured the amount of carrot ingested on each day of conditioning (weighing before and after conditioning) in order to determine whether or not the groups differed in the amount they ate. The conditioning treatment lasted 6 days for both groups, with one trial per day. On Day 7, all snails were individually tested with the apple odor following the same procedure as that used in the pretest. The snails were tested in random order, and the experimenter was unaware of their experimental history.

\section{Results and Discussion}

Initial tentacle lowering behavior is critical, and the pretest data are presented in Figure 1A. In the pretest, animals in paired and unpaired groups showed an average of 3.5 and 2.7 tentacle lowering responses, respectively. After conditioning (the posttest data in the figure), the equivalent scores were 6.2 and 3.4. An ANOVA with test day and group as factors revealed a significant effect of day $[F(1,8)=5.4, p<.05]$ but no effect of group $[F(1,8)=2.22, p>.05]$. The interaction was not significant $[F(1,8)=3.02, p>.05]$. Nevertheless, a one-way ANOVA conducted on each test day showed no effects in pretest $[F(1,11)=0.43, p>.05]$ but a significant difference in the posttest $[F(1,9)=7.84, p<.05]$.

The results for the paired group are what would be expected if feeding in the presence of a particular odor endowed this odor with appetitive properties; that is, during the presentation of the CS in the test trial, the subjects in the CS-US condition (the paired group) exhibited increased frequency of tentacle lowering behavior, in comparison with the level of this response among the subjects in the unpaired control group.

It has been argued (by Farley, Jin, Huang, \& Kim, 2004) that nonassociative learning effects (mainly attenuation of habituation) could produce effects like those expected from associative learning. The initial report of the tentacle lowering response in Helix by Peschel, Straub, and Teyke (1996) showed that naive snails sometimes lowered their tentacles in response to novel odors. This response might decline (i.e., habituate) for animals in the unpaired 


\section{A}

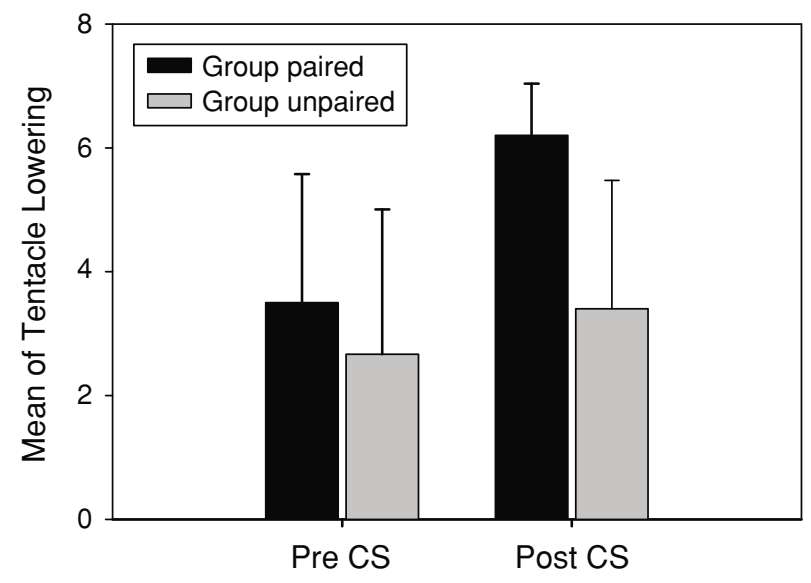

B

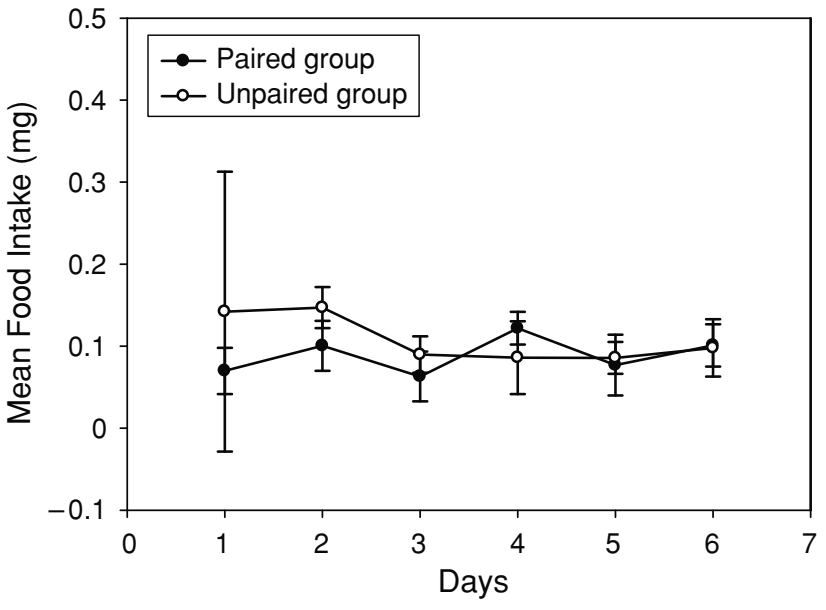

Figure 1. (A) Results of Experiment 1A: Acquisition. Mean number of tentacle lowering responses made by Group Paired and Group Unpaired during CS (apple) prior to conditioning and after treatments. (B) Carrot ingested in Experiment $1 \mathrm{~A}$. Mean amount (mg) of carrot ingested by Group Paired (filled circles) and Group Unpaired (open circles) during the 6 trials of conditioning in Experiment 1A. Vertical bars represent standard errors of the mean.

group, but remain elevated for animals in the paired group because feeding concurrent with exposure to the CS interferes with the processes of habituation. The outcome could be a higher level of response on the final test in Group Paired rather than Unpaired. The pretest results of the present experiment argue against this nonassociative interpretation of our results. Our snails did not show high levels of tentacle lowering before conditioning, and pairing the CS with the US increased the level of response in Group Paired rather than merely attenuated its habituation. Experiment 1B provided further data relevant to this issue.

The difference between the groups is not to be explained in terms of a difference in their experience of the US. The amount of carrot ingested by each group on each trial is depicted in Figure 1B. In the two initial trials, animals in Group Unpaired ate slightly more than animals in Group Paired; but this difference diminished over trials, and there were no differences at the end of the conditioning. A repeated measures ANOVA showed no effect of days $[F(5,45)=1.53, p>.05]$, no effect of groups $[F(1,9)=2.24, p>.05]$, and no interaction $[F(5,45)=$ $2.15, p>.05]$. Therefore, there were no relevant differences between Groups Paired and Unpaired in their experience with the US.

\section{EXPERIMENT 1B}

As we have noted, it has been argued (Farley et al., 2004) that various nonassociative processes, alone or in combination, can masquerade as associative learning effects, and that these are especially potent in chemosensory conditioning. Therefore, we thought it important to replicate the main result obtained in Experiment $1 \mathrm{~A}$ and to offer more evidence against alternative explanations. Al- though Experiment 1A clearly showed evidence indicating low levels of response in snails prior to conditioning, there was another design that could offer an evaluation of attenuation of habituation as an alternative interpretation. This was to compare the performance of conditioned animals with that of animals that had received no prior training (see Ungless, 2001). Accordingly, we conducted a replication of Experiment 1A comparing the usual paired and unpaired groups with a naive group. Groups Paired and Unpaired received the same treatment as did the animals in Experiment 1A (but without pretest); animals in the control group received six 10-min periods of access to carrot in a different context. If animals in this group showed levels of CRs similar to those in Group Paired, this would accord with the habituation explanation. If animals in the control group responded like animals in Group Unpaired, we could assume that associative learning has played a role in the snails' behavior.

\section{Method}

The subjects were 18 snails taken from the wild, with a shell diameter of $25 \mathrm{~mm}$ (range, $30-38 \mathrm{~mm}$ ) at the start of the experiment. All the housing and maintenance details were exactly the same as in Experiment 1A.

After the 10-day deprivation period, the snails were randomly assigned to three equal-sized groups $(n=6)$. Animals in the paired and unpaired groups received exactly the same treatment as did the animals in Experiment 1A. The animals in the control group were given equivalent access to carrot in a different place for 6 days. The test trial was the same for all the animals: a 2-min period of exposure to the CS, during which the snail's left posterior tentacle was observed.

\section{Results and Discussion}

The tentacle lowering responses for the three groups are presented in Figure 1C. The mean scores for the paired, unpaired, and control groups were 6.8, 2.7, and 


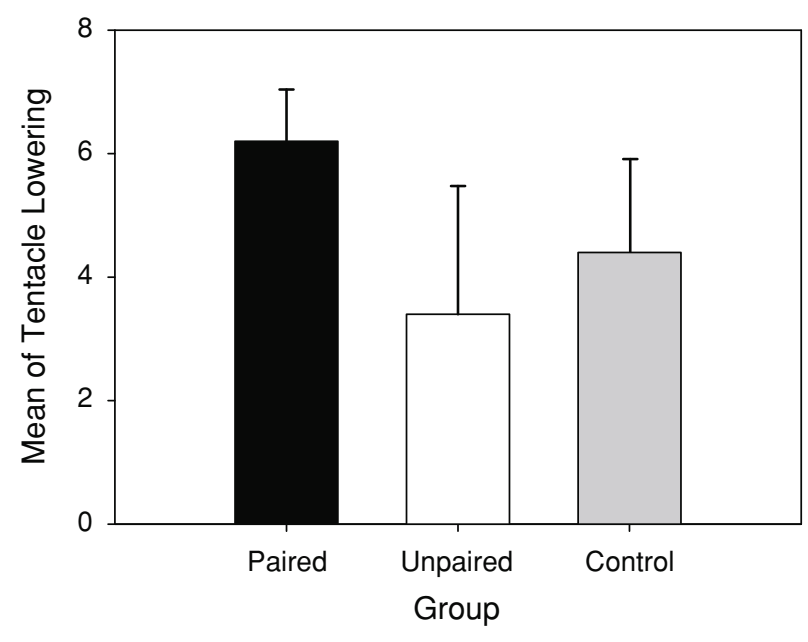

Figure 1 (continued). (C) Results of Experiment 1B. Mean number of tentacle lowering responses made by paired, unpaired, and control groups during the test with the CS after conditioning. Vertical bars represent standard errors of the mean.

4.0, respectively. After conditioning, the animals in Group Paired produced more CRs than did those in the unpaired and control groups, although the control score was somewhat higher than that for unpaired. A one-way ANOVA showed that these differences were significant $[F(2,17)=$ $16.86, p<.05]$. But Tukey's test showed significant differences between paired and unpaired, and between paired and control, but not between unpaired and control. This pattern of results could not be explained in terms of attenuation of habituation, and we concluded that the response shown in the paired group was a consequence of Pavlovian conditioning. We then proceeded to determine whether other Pavlovian phenomena such as latent inhibition, overshadowing, second-order conditioning, and sensory preconditioning would be observed with this procedure.

\section{EXPERIMENT 2}

The results for the paired groups of Experiment $1 \mathrm{~A}$ and $1 \mathrm{~B}$ demonstrated the formation of an association between the apple odor and the taste and/or nutritive properties of the carrot. It should be possible to modulate the strength of this association in predictable ways by manipulating the variables effective in standard conditioning paradigms. In Experiment 2, we sought evidence that the postulated association was sensitive to latent inhibition.

When a subject is repeatedly exposed to a neutral stimulus, subsequent conditioning is retarded when that stimulus is used as a CS (Lubow, 1973, 1989). This effect, known as latent inhibition, is said to reflect a loss of attention to the familiar stimulus. To demonstrate this phenomenon in our procedure, experimental snails were given experience of an odor alone before being given training in which they were exposed to odor-carrot pairings. If latent inhibition occurred, then these subjects (the preexposed group) should show less tentacle lowering when subsequently tested with the conditioned odor than would control subjects given preexposure to a different, but presumably irrelevant, odor. Table 1 presents a summary of the experimental design.

\section{Method}

The subjects were 12 snails taken from the wild, with a mean shell size of $29 \mathrm{~mm}$ (range, 25-34 mm) at the start of the experiment. All the housing and maintenance details were exactly the same as in Experiment $1 \mathrm{~A}$.

After the 10-day deprivation period, the snails were randomly assigned to two equal-sized groups $(n=6)$. The animals in both groups received a 10-min period of exposure to the odor produced by a slice of fruit on each of the 6 days of the preexposure phase. For half of the animals in each group, the odor was of apple; for half, it was pear. In the 2 days following preexposure, all the animals received $10 \mathrm{~min}$ of free access to a piece of carrot (approximately $1 \mathrm{~cm}^{2}$ ) in the presence of one of the odors as in Experiment 1A. For the animals in the preexposed group this was the preexposed odor; for the control animals, it was the other odor. The next day, after these two conditioning sessions, all the snails received a test trial in which the conditioned odor was presented and the snail's left posterior tentacle movement was recorded for $2 \mathrm{~min}$. This 3-day training cycle was repeated two more times, so that the snails received a total of six conditioning trials and three test trials.

\section{Results and Discussion}

Figure 2 shows the mean number of tentacle lowering responses made by the preexposed and control groups during the three test trials. The snails in the preexposed group showed consistently fewer CRs than the snails in the control group. A two-way repeated measures ANOVA conducted on the data summarized in the figure, with day and group as the variables, revealed significant main effects of group $[F(1,9)=70.35, p<.05]$ and of day $[F(2,18)=63.12$, $p<.05]$. The interaction was not significant $[F(2,18)=$ $1.09, p>.05]$. The difference between the groups was significant on each of the three test trials $[t(9)=-4.29$; $t(9)=-7.40 ; t(9)=-7.02 ; p \mathrm{~s}<.05]$.

The results obtained in Experiment 2 were what would be expected if preexposure to an odor produced a latent inhibition effect that attenuated the effectiveness of the

Table 1

Design of Experiments 2, 4, and 6 (Between Subjects)

\begin{tabular}{|c|c|c|c|c|}
\hline Experiment & Group & Preexposure & Conditioning & Test \\
\hline $2(\mathrm{LI})$ & $\begin{array}{l}\text { PREE } \\
\text { CTRL }\end{array}$ & $\begin{array}{l}6 \mathrm{CS} 1 \\
6 \mathrm{CS} 2\end{array}$ & $\begin{array}{l}6 \mathrm{CS} 1 \rightarrow \mathrm{US} \\
6 \mathrm{CS} 1 \rightarrow \mathrm{US}\end{array}$ & $\begin{array}{l}3 \text { CS1 } \\
3 \text { CS1 }\end{array}$ \\
\hline $4(\mathrm{OV})$ & $\begin{array}{l}\text { COM } \\
\text { ELE }\end{array}$ & & $\begin{array}{l}6 \mathrm{CS} 1+\mathrm{CS} 2 \rightarrow \mathrm{US} \\
6 \mathrm{CS} 2 \\
6 \mathrm{CS} 1 \rightarrow \mathrm{US}\end{array}$ & $\begin{array}{l}\mathrm{CS} 1 \\
\mathrm{CS} 1\end{array}$ \\
\hline 6 (SPC) & $\begin{array}{l}\text { COM } \\
\text { ELE }\end{array}$ & $\begin{array}{l}6 \mathrm{CS} 1+\mathrm{CS} 2 \\
6 \mathrm{CS} 2 \\
6 \mathrm{CS} 1\end{array}$ & $\begin{array}{l}\mathrm{CS} 1 \rightarrow \mathrm{US} \\
\mathrm{CS} 1 \rightarrow \mathrm{US}\end{array}$ & CS2 \\
\hline
\end{tabular}

Note-LI, latent inhibition; OV, overshadowing; SPC, sensory preconditioning. PREE refers to the preexposed group; CTRL to the control group. COM refers to the group that received the compound stimulus; ELE refers to the group that received simple conditioning to elements of the compound on separate trials. For half of the animals, CS1 was apple, and for the other half, pear. The same was true for CS2. The US was always carrot. 


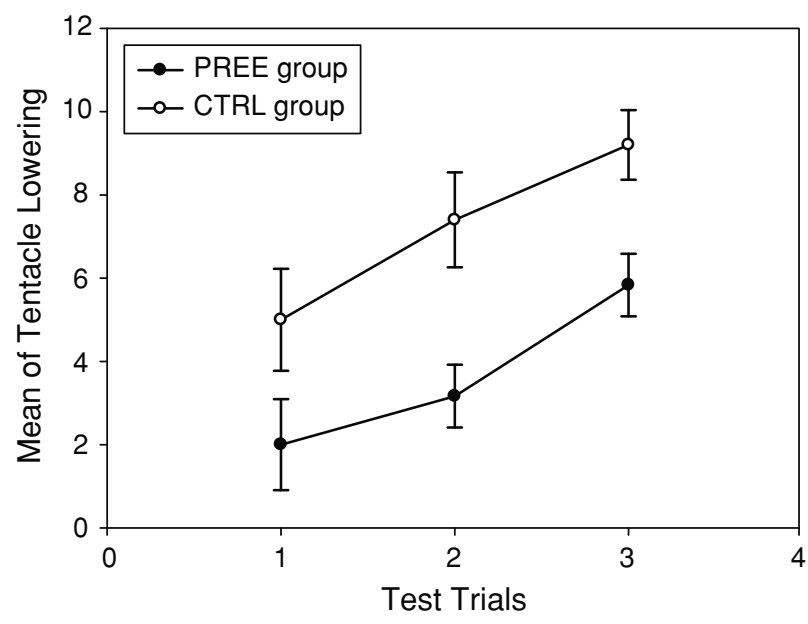

Figure 2. Results of Experiment 2: Latent inhibition. Mean number of tentacle lowering responses made by the preexposed group (PREE) and nonpreexposed group (CTRL) during the three test trials. Vertical bars represent standard errors of the mean.

odor-carrot pairing. The fact that the magnitude of the CR increased over successive test trials in this experiment allowed us to address the nonassociative explanation of Experiments 1A and 1B. In Experiment 2, we made use of a three-test-trial procedure and found that the level of $\mathrm{CR}$ was smaller at the beginning than at the end of training. Statistical analysis confirmed this result. A repeated measures ANOVA only for animals in the control group (a group that received simple conditioning) conducted over the three test trials revealed a significant effect of days $[F(2,8)=41.6, p<.05]$. This increase in responding cannot be explained in terms of attenuation of habituation.

\section{EXPERIMENT 3}

In Experiment 3, we tried to confirm the results of Experiment 2 , using a within-subjects design in which all animals were preexposed to one odor and then received conditioning both with the preexposed odor and with a novel odor.

\section{Method}

The subjects were 12 snails taken from the wild, with a mean shell size of $32 \mathrm{~mm}$ (range, 28-34 mm) at the start of the experiment. All the housing and maintenance details were exactly the same as in Experiment 1A.

After the 10-day deprivation period, half of the snails received a 10-min period of exposure to a slice of apple and the other half received a 10-min period of exposure to a slice of pear on each of the 6 days of the preexposure phase. Therefore, each snail had experience with just one odor in this stage of training. The design is summarized in Table 2.

On the 4 days following preexposure, all the animals received daily trials consisting of $10 \mathrm{~min}$ of access to a piece of carrot (approximately $1 \mathrm{~cm}^{2}$ ), twice in the presence of apple and twice in the presence of pear. The order was counterbalanced; that is, for half of the animals ( 3 preexposed to apple and 3 preexposed to pear), the first odor was apple, and for the remaining half, the first odor was pear. After these four conditioning trials, all the snails received two test trials, with a slice of apple on one day and with a slice of pear on another. On each trial, the snail's left posterior tentacle movement was recorded for $2 \mathrm{~min}$. This 6-day training cycle was repeated two more times, so that the snails received a total of six conditioning trials with each of the odors and three test trials with each of the odors.

\section{Results and Discussion}

Figure 3 shows the mean number of tentacle lowering responses made by the snails in the presence of the preexposed CS and in the presence of the nonpreexposed $\mathrm{CS}$ on each of the test trials. Although there was no difference on the first trial, the means for the second and third trials showed fewer CRs in the presence of the preexposed CS than in the presence of the nonpreexposed CS. An ANOVA conducted on the data summarized in the figure, with day and preexposure as the variables, revealed significant effects of preexposure $[F(1,11)=27.06, p<$ $.05]$ and of day $[F(2,22)=106.41, p<.05]$, and a significant interaction $[F(2,22)=4.39, p<.05]$. The difference between the groups was not significant in the first test trial $[t(11)=-0.89, p>.05]$ but was significant in the second $[t(11)=-4.18, p<.05]$ and in the third $[t(11)=$ $-4.39, p<.05]$ test trial.

These results confirmed the previous finding that preexposure to an odor produced a latent inhibition effect that attenuated the effectiveness of the odor-carrot pairing.

\section{EXPERIMENT 4}

Overshadowing is an important phenomenon because it shows that mere contiguity is not enough to promote conditioning. The aim of this experiment was to seek an overshadowing effect in the tentacle lowering procedure. The results so far indicated that giving snails a number of pairings of an odor (CS) with carrot (US) led to the formation of an association between the odor and the nutritional consequences of eating carrot. An overshadowing effect would be demonstrated if the addition of another odor stimulus (CS2) prevented or attenuated acquisition by the other odor (CS1). Accordingly, in Experiment 4, one group of snails (compound) was presented with a compound stimulus consisting of a piece of apple and a piece of pear, presented at the same time, while eating carrot. After this treatment they received a test with one of these odors (see Table 1). A control group received simple conditioning with an odor and exposure to the other alone, thus being matched to the compound group in their experience of the odors. If overshadowing occurred, the animals

Table 2

Design of Experiment 3: Latent Inhibition (Within Subjects)

\begin{tabular}{|c|c|c|c|c|}
\hline Preexposure & Conditioning & Test 1 & & Test 2 \\
\hline $6 \mathrm{CS} 1$ & $\begin{array}{l}6 \mathrm{CS} 1 \rightarrow \mathrm{US} \\
6 \mathrm{CS} 2 \rightarrow \mathrm{US}\end{array}$ & CS1 & vs. & $\mathrm{CS} 2$ \\
\hline
\end{tabular}

Note-For half of the animals, CS1 was apple, and for the other half, pear. The same was true for CS2. The US was always carrot. 


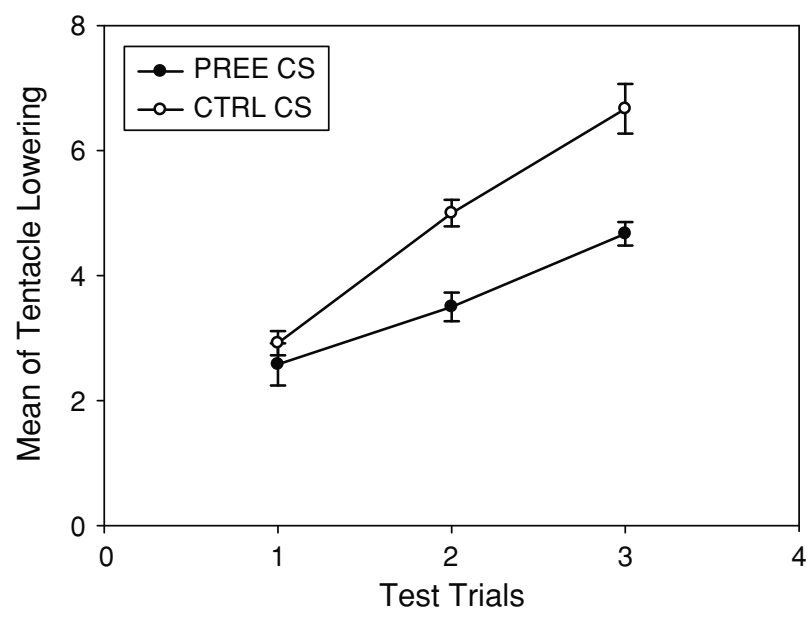

Figure 3. Results of Experiment 3: Latent inhibition in a withinsubjects design. Mean number of tentacle lowering responses made by the same subjects during preexposed CS (PREE) and nonpreexposed CS (CTRL) over the three test trials. Vertical bars represent standard errors of the mean.

trained with both CSs (the compound group) should show less tentacle lowering to the test odor than should snails in the control condition.

\section{Method}

The subjects were 12 snails taken from the wild, with a mean shell size of $34 \mathrm{~mm}$ (range, 29-37 mm) at the start of the experiment. All the housing and maintenance details were exactly the same as in Experiment 1A.

The conditioning phase lasted 12 days. On 6 of these days, the snails in the compound group received a 10 -min period of exposure to a slice of apple plus a slice of pear while they had the opportunity to eat carrot. On the remaining 6 days, they received no training. Animals in the control group received a 10-min period of exposure to CS1 (for half of the animals, a slice of apple, and for half of the animals, a slice of pear), with the opportunity to eat carrot, on 6 of the 12 days of the conditioning phase. On the remaining 6 days, they received a 10-min exposure to CS2 (pear or apple). That is, they received preexposure to the elements of the compound on separate trials. After these six conditioning trials, all the snails received a test trial with a slice of CS1 (in the compound group, half of the snails received apple, and the other half received pear). The snail's left posterior tentacle movement was recorded for $2 \mathrm{~min}$.

\section{Results and Discussion}

Figure 4 shows the mean number of tentacle lowering responses made by the compound group in comparison with controls. It appears that the presence of an additional odor on the conditioning trials overshadowed learning about the other odor of the compound; the compound group showed less of an appetitive response to CS1 than did controls. A one-way ANOVA with the data from the test trial confirmed this conclusion $[F(1,11)=15.93, p<$ $.05]$. Like all demonstrations of overshadowing, this instance is open to a number of explanations (e.g., in terms of generalization decrement effects, or in terms of the cue-competition effects postulated by formal models of conditioning such as that proposed by Rescorla \& Wagner,
1972). Nonetheless, the effect obtained here exactly paralleled the one observed using more orthodox conditioning procedures.

\section{EXPERIMENT 5}

Higher order conditioning can be considered cognitively more demanding than simple conditioning, making demonstrations of second-order conditioning in invertebrate species particularly relevant from a comparative point of view. Sahley et al. (1981) have provided evidence for second-order conditioning with an aversive procedure in Limax maximus. Given that our procedure proved effective in replicating a number of associative phenomena, it was possible that snails would show a conditioned tentacle lowering response in the presence of a CS (CS2) that had never been paired with the carrot US directly, but that had been paired with another CS (CS1) that had been paired previously with the US. In Experiment 5, we explored this possibility in a within-subjects design.

\section{Method}

The subjects were 8 snails taken from the wild with a mean shell size diameter of $27 \mathrm{~mm}$ (range, $23-31 \mathrm{~mm}$ ) at the start of the experiment. One snail died during the course of the experiment, and therefore some results are available for only 7 subjects. All the housing and maintenance details were exactly the same as in Experiment 1A. In Experiment 5, we used two novel odors (banana and strawberry) in addition to the previous apple and pear odors. The US was always carrot.

The procedure for the conditioning and test trials was the same as that described for the previous experiments. Thus, conditioning trials lasted $10 \mathrm{~min}$ (for both first- and second-order conditioning) and test trials lasted $2 \mathrm{~min}$. CRs were measured as in the previous experiments. Apple and pear were counterbalanced, so during first-order conditioning, half of the animals received pairings of apple and carrot with pear presented separately as a control. For the remaining

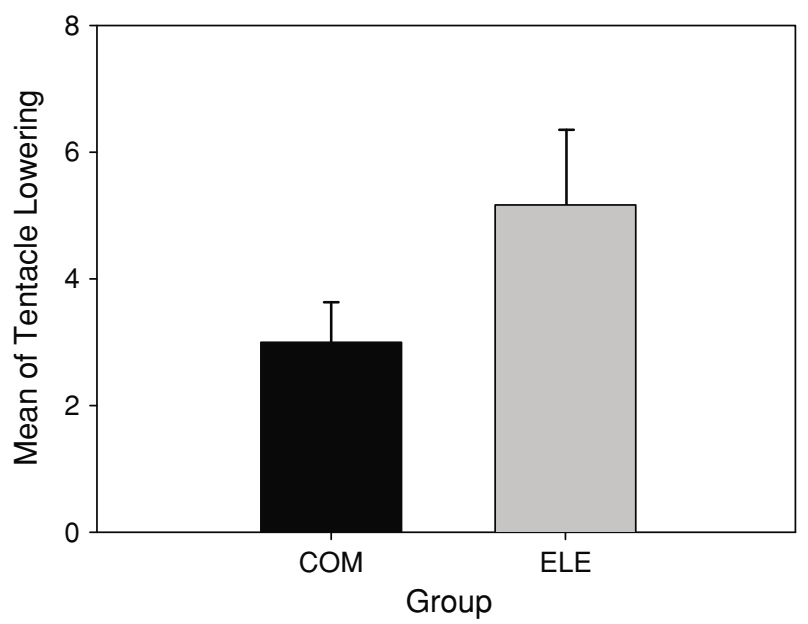

Figure 4. Results of Experiment 4: Overshadowing. Mean number of tentacle lowering responses during test trials with CS1 (apple or pear) by group training with a compound of apple and pear (COM) and group training with the separated elements (ELE). 
half, pear was the experimental CS (paired with carrot) and apple was the control CS (presented alone in a separate session). We refer to the paired CS as CS1+ and to the control as CS2. All the animals received a 6-day training cycle in the first-order conditioning phase. On 2 of these days, the snails received $10 \mathrm{~min}$ of access to a piece of carrot (approximately $1 \mathrm{~cm}^{2}$ ) in the presence of the CS (apple or pear), and on 2 days, they received exposure only to the control CS (nonpaired). The order was counterbalanced. After these four trials, all the snails received two test trials: on one day with a slice of apple, and on another day with a slice of pear. In both cases, the snail's left posterior tentacle movement was recorded for $2 \mathrm{~min}$. This 6-day training cycle was repeated two more times, so that snails received two conditioning trials, two control trials, and two tests until they had experienced a total of six conditioning trials, six exposures to control CS, and three intermixed test trials with each of the odors (three with the paired CS and three with an unpaired one). Therefore, this phase lasted 18 days, 6 for paired presentations, 6 for unpaired presentations, and 6 for intermixed tests.

During second-order conditioning, there were two types of trials. In the second-order trials, the previously conditioned odor (CS1+) and a novel odor (CS3) were presented together for $10 \mathrm{~min}$. Immediately after this compound presentation, we gave a test trial in which the second-order CS (CS3) was presented for 2 min, during which tentacle lowering was scored. In control trials, the preexposed control odor (CS2) was presented together with a novel odor (CS4), followed by a test with the novel odor (CS4). This phase lasted for 16 days (eight second-order and test trials and eight control and test trials). We counterbalanced the new CS in both subgroups. Of the snails that received apple as CS1+, half received banana as secondorder CS3 and the other half (i.e., 2 snails) received strawberry as second-order CS3. The same was true for the 4 snails receiving pear as the first-order CS1+. Table 3 summarizes the experimental design.

\section{Results}

To analyze the data, all the CSs were functionally collapsed - that is to say, first-order CSs with first-order CSs, control first-order CSs with control first-order CSs (these were apple or pear), second-order CSs with secondorder CSs, and their respective controls together (these were banana or strawberry). During first-order conditioning, the level of CR during the presence of the CS paired with carrot $(\mathrm{CS} 1+)$ was higher than that during the control CS (CS2) (see Figure 5A). An ANOVA conducted on the data summarized in Figure 5A, with trials and CSs as the variables, revealed significant effects of trials $[F(2,14)=$ $62.06, p<.05]$ and CSs $[F(1,7)=126.45, p<.05]$, and a significant interaction $[F(2,14)=9.29, p<.05]$. The

Table 3

Design of Experiment 5: Second-Order Conditioning (Within Subjects)

\begin{tabular}{ccc}
\hline $\begin{array}{c}\text { First-Order } \\
\text { Conditioning }\end{array}$ & $\begin{array}{c}\text { Second-Order } \\
\text { Conditioning }\end{array}$ & Test \\
\hline $6 \mathrm{CS} 1 \rightarrow \mathrm{US}$ & $8(\mathrm{CS} 3 \rightarrow \mathrm{CS} 1)$ & \\
$6 \mathrm{CS} 2$ & $8(\mathrm{CS} 4 \rightarrow \mathrm{CS} 2)$ & \\
\hline
\end{tabular}

Note-Arrows reflect simultaneous presentation. For half of the animals, CS1 was apple, and for the other half, pear. The same was true for CS2. For half of the animals, CS3 was banana, and for the other half, strawberry. The same was true for CS4. The US was always carrot. Testing with CS3 and CS4 occurred immediately after each second-order conditioning trial. difference between the CSs in each of the test trials was significant $[t \mathrm{~s}(7)=5.7,5.8$, and $17.1 ; p \mathrm{~s}<.05]$.

Figure $5 \mathrm{~B}$ shows the group mean scores for successive tests with second-order CSs and control CSs during the second-order conditioning phase. As demonstrated in the figure, up to the fourth trial, snails showed an increasing tendency to show tentacle lowering in the presence of the second-order CS (and not in the presence of the control CS). From the fourth trial on, the difference between the stimuli was maintained, although the level of response to the second-order CS decreased. This decrease in responding was probably due to extinction, given that the procedure involved exposure to the CS for 10 min without nutritional consequences. An ANOVA with days and CSs as factors confirmed this description, revealing significant effects of days $[F(7,49)=9.48, p<.05]$ and CSs $[F(1,7)=266.44, p<.05]$, and a significant interaction $[F(7,49)=12.81, p<.05]$. The difference between the CSs was significant on all but the first and the last of the test trials [for the other 6 trials, $t \mathrm{~s}(7)>3.55, p \mathrm{~s}<.05$ ]

These results showed that snails could develop not only an association between a neutral odor and subsequent nutritional consequences, but also an association between a neutral odor and another odor previously paired with nutritional consequences. This constitutes evidence indicating higher order conditioning in an appetitive procedure with snails as subjects.

\section{EXPERIMENT 6}

Evidence for sensory preconditioning in gastropod molluscs comes from a study by Suzuki, Sekiguchi, Yamada, and Mizukami (1994), who used Limax flavus as subjects, odors as CSs, and quinidine sulfate solution as the US. In a more recent study exploring sensory preconditioning in the pond snail, Lymnaea stagnalis, Kojima et al. (1998) used an appetitive sucrose solution and a weak vibration as CSs and an aversive $\mathrm{KCl}$ solution as the US. These experiments found clear evidence of a sensory preconditioning effect in an aversive procedure. It seemed likely, therefore, that this associative phenomenon would also occur with our appetitive procedure. Subjects in the experimental condition of Experiment 6 were given initial exposure to a compound of apple and pear before being allowed to consume carrot in the presence of one of the odors. We predicted that the association between the trained odor and nutritional consequences of the carrot ingestion would endow the other odor with conditioned properties by virtue of the apple-pear association formed during the first phase of training.

\section{Method}

The subjects were 24 snails taken from the wild, with a mean shell size diameter of $28 \mathrm{~mm}$ (range, $22-35 \mathrm{~mm}$ ) at the start of the experiment. One snail died during the experiment; therefore some results were obtained for only 23 subjects. The housing and maintenance details were exactly the same as in Experiment 1A.

The experimental design is given in Table 1 , where the experimental group is designated as COM (for compound preexposure) and the control group is labeled as ELE because it was given preexposure 
A

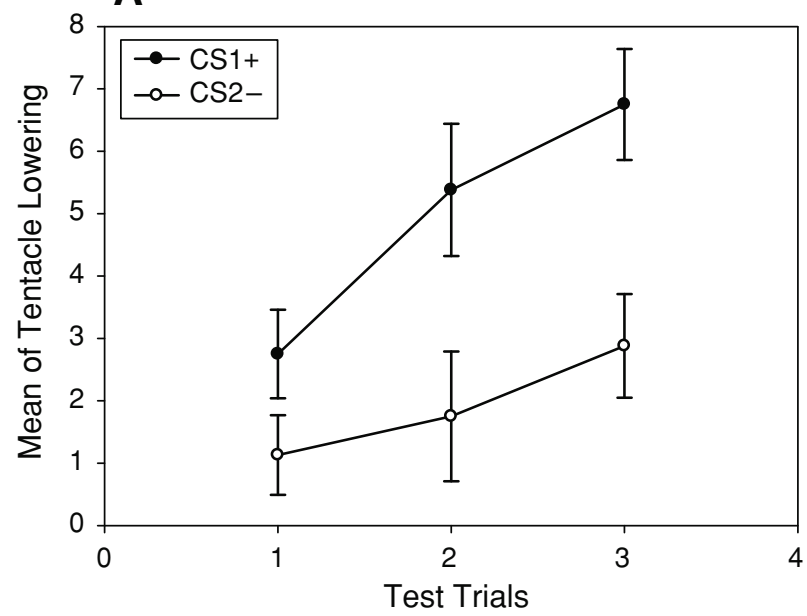

B

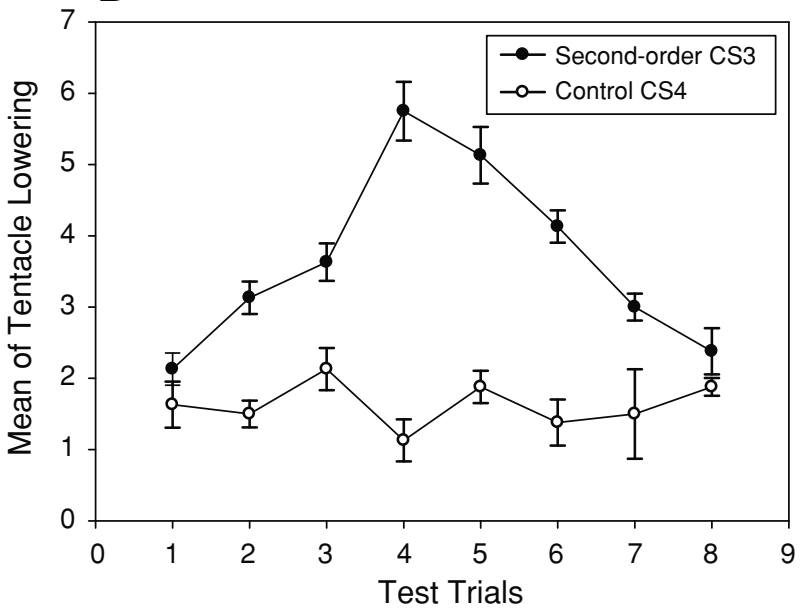

Figure 5. (A) Experiment 5: Phase 1, first-order conditioning. Mean number of tentacle lowering responses made during test trials with CS paired with carrot (filled circles: CS1+) and during the test trials with the control CS (open circles: CS2-). For half of the animals, CS1+ was pear, and for half, apple. The same was true for CS2-. (B) Experiment 5: Phase 2, second-order conditioning. Mean number of tentacle lowering responses made during test trials with second-order CS3 (filled circles) and during the test trial with the control second-order CS4 (open circles). Vertical bars represent standard errors of the mean.

to elements of the compound, apple and pear, on separate trials. The preexposure phase lasted 6 days. On each day, the animals were exposed to odors for $10 \mathrm{~min}$. Subjects in the compound group received six presentations of the apple-pear compound. Subjects in the elements group received presentations of apple and pear with a 1-h delay between them. After preexposure, simple conditioning began. Half of the animals in the compound group and half of the animals in the elements group were conditioned using apple as CS, while the remaining half were conditioned using pear. During conditioning, 2 days of conditioning trials were followed by one test trial (with the conditioned odor) in which, as usual, we counted the number of left tentacle lowerings for $2 \mathrm{~min}$. This 3-day cycle was presented three times, making a total of six conditioning trials and three intermixed test trials. The following day constituted the test phase. In it, all the animals were exposed to the odor CS that was not employed during conditioning. Any procedural details not specified here were the same as those described for the previous experiments.

\section{Results and Discussion}

Group mean scores for the test trials of the conditioning phase are presented in Figure 6A. As the figure shows, both groups acquired the $\mathrm{CR}$ and there was no difference between them in the number of tentacle lowering
A

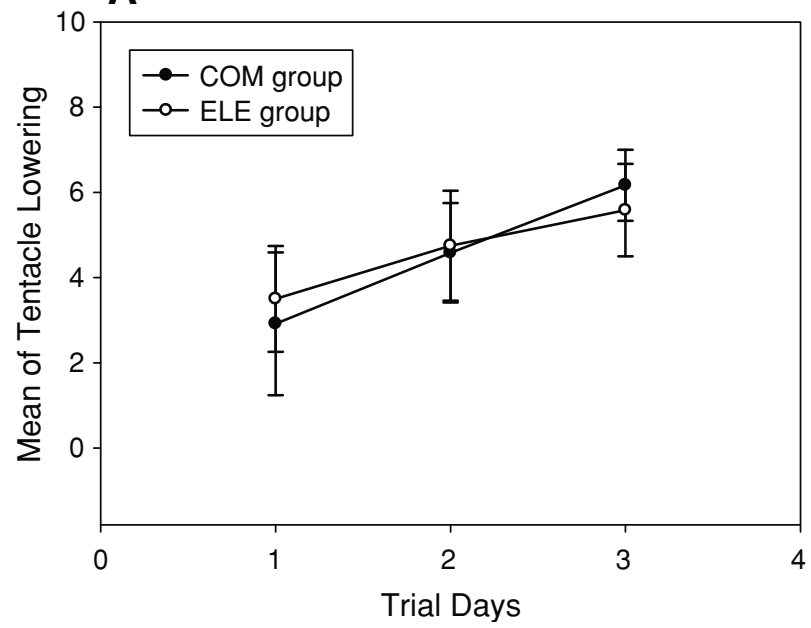

B

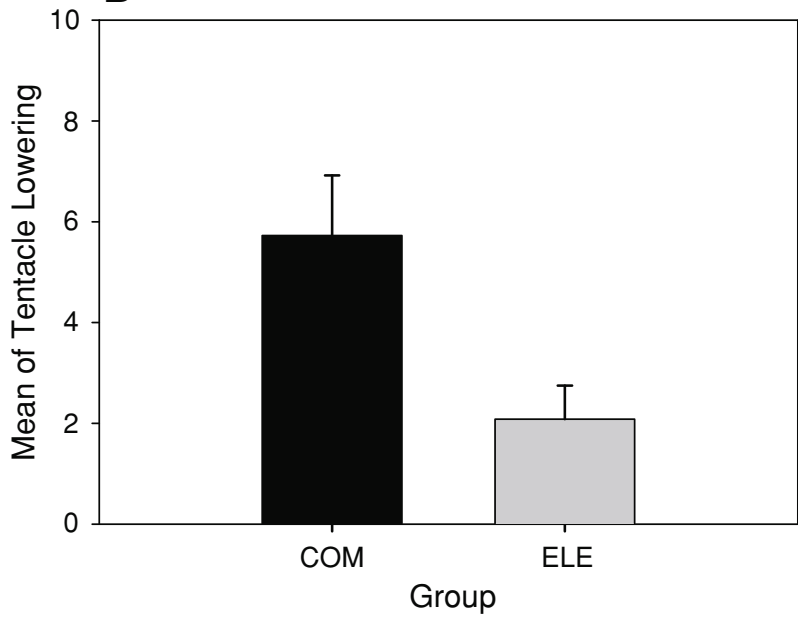

Figure 6. (A) Experiment 6: Sensory preconditioning, conditioning phase. Mean number of tentacle lowering responses made during the three test trials of conditioning by group preexposed to compound (COM) or preexposed to the elements (ELE). (B) Experiment 6: Sensory preconditioning, test. Mean number of tentacle lowering responses made during the test trial with the sensorially preconditioning CS by group preexposed to compound (COM) or preexposed to the elements (ELE). Vertical bars represent standard errors of the mean. 
responses during the conditioning test trials. An ANOVA was conducted on the test data summarized in the figure, with group and trial as the variables, revealing a significant main effect of trial $[F(2,44)=30.92, p<.05]$, but no difference between the groups $[F(1,22)=0.03, p>.05]$ and no interaction $[F(2,44)=1.52, p>.05]$.

The results of central interest come from the test trial with the odor that had not been paired with carrot. As Figure $6 \mathrm{~B}$ shows, snails in the compound group lowered their tentacles more often than did those in the elements group. A one-way ANOVA conducted on the data for the test trial revealed a significant difference between the groups $[F(1,22)=83.79, p<.05]$. This result is consistent with the hypothesis that the treatment given to the compound group generates a sensory preconditioning effect that depends on the formation of an association between the odors of apple and of pear in the preexposure phase, and the establishment of an association between the CS and nutritional consequences of carrot ingestion in the conditioning phase.

\section{GENERAL DISCUSSION}

Early observations of the phenomenon of tentacle lowering in the snail were interpreted as reflecting a specific adaptation for olfaction-based foraging behavior (Peschel et al., 1996). Direct studies of related effects under laboratory conditions (e.g., Teyke, 1995; Ungless, 1998, 2001) have suggested a Pavlovian interpretation of these behavior changes in snails. The results of our experiments establish the reliability of tentacle lowering as a learning procedure and support the interpretation of this effect in terms of standard principles of Pavlovian conditioning. These findings are of interest, in part, because, unlike the findings in the majority of the studies with invertebrates, in which special learning procedures are used (see Abramson, 1994), these were obtained with a training procedure that closely paralleled the standard appetitive training procedures used with vertebrates.

The results obtained with our procedure are consistent with the proposal that simply consuming food (carrot) in the presence of an odor engages a conditioning mechanism that results in the formation of an association between the odor and the nutritional consequences of carrot ingestion. Snails were found to lower their tentacles when they perceived the odor of the CS that was paired with the eating of the carrot, and this CR was not due to attenuation of response habituation (Experiments $1 \mathrm{~A}$ and $1 \mathrm{~B}$ ). Preexposure to the odor prior to conditioning retarded the development of a conditioned response to the odor (Experiments 2 and 3 ). These results suggest that the learning that occurs as a consequence of the ingestion of carrot in the presence of an odor CS is subject to latent inhibition. Another odor present during consumption of carrot restricted the extent to which the target odor acquired the power to elicit tentacle lowering (the overshadowing effect of Experiment 4). Another associative phenomenon was observed in Experiment 5, in which we paired a new odor
CS not with a US, but with a previously conditioned CS. The snails showed more tentacle lowering in the presence of this odor than in the presence of a control odor; that is to say, they showed second-order conditioning. Conditioning, latent inhibition, overshadowing, and second-order conditioning share a common associative dynamic; all of them are proactive information processing phenomena. In Experiment 6, we provided evidence that snails can develop retroactive information processing in a sensory preconditioning design. If snails experience the simultaneous odors of two CSs without any consequence (nonreinforced preexposure), these stimuli form an association that, after the subsequent conditioning of one of these CSs, allows the other CS (never before paired with the US) to elicit tentacle lowering.

It seems likely that the associative learning processes observed in these experiments play an important role in the process whereby an animal comes to establish its dietary preferences (see, e.g., Bolles, 1983, for a discussion of the application of this principle to the development of preferences as well as aversions). More generally, it is also possible that even experience of motivationally neutral stimuli may allow associations to form between their immediate properties and their aftereffects that will act to modify the animal's subsequent response to these stimuli.

The relationship between conditioning and animal cognition is a matter of debate. On the one hand, some authors have based their research on the notion that conditioning is a basic mechanism from which cognition derives (e.g., Hall, 1991; Pearce, 1987). On the other hand, other authors have tried to argue that cognition goes beyond the processes that allow an animal to show conditioning (e.g., Greenberg \& Haraway, 2002; Roitblat, 1987). In either case, information on how any given species behaves when subjected to standard conditioning procedures is a necessary first step in developing a full account of comparative cognition.

\section{REFERENCES}

ABRAmson, C. I. (1994). A primer of invertebrate learning: The behavioral perspective. Washington, DC: American Psychological Association.

Bolles, R. C. (1983). A "mixed model” of taste preference. In R. L. Mellgren (Ed.), Animal cognition and behavior (pp. 65-82). Amsterdam: North-Holland.

Burrell, B. D., \& SAhley, C. L. (2001). Learning in simple systems. Current Opinion in Neurobiology, 11, 757-764.

Carlson, N. J. (1994). Physiology and behavior. Boston: Allyn \& Bacon.

Carretta, D., Hervé-Minvielle, A., Bajo, V. M., Villa, A. E. P., \& Rouiller, E. M. (1999). c-Fos expression in the auditory pathways related to the significance of acoustic signals in rats performing a sensory-motor task. Brain Research, 841, 170-183.

FARley, J., Jin, I., HuANG, H., \& KIM, J.-I. (2004). Chemosensory conditioning in molluscs: II. A critical review. Learning \& Behavior, 32, 277-288.

Greenberg, G., \& Haraway, M. M. (2002). Principles of comparative psychology. Boston: Allyn \& Bacon.

Hall, G. (1991). Perceptual and associative learning. Oxford: Oxford University Press, Clarendon Press.

KoJima, S., Kobayashi, S., YamanaKa, M., Sadamoto, H., NaKamura, H., 
FUIITO, Y., ET AL. (1998). Sensory preconditioning for feeding response in the pond snail, Lymnaea stagnalis. Brain Research, 808, 113-115.

Lubow, R. E. (1973). Latent inhibition. Psychological Bulletin, 79, 398407.

LUBOw, R. E. (1989). Latent inhibition and conditioned attention theory. Cambridge: Cambridge University Press.

Metz, G. A., \& Whishaw, I. Q. (2002). Cortical and subcortical lesions impair skilled walking in the ladder rung walking test: A new task to evaluate fore- and hindlimb stepping, placing, and co-ordination. Journal of Neuroscience Methods, 115, 169-179.

Pearce, J. (1987). An introduction to animal cognition. Hillsdale, NJ: Erlbaum.

Peschel, M., Straub, V., \& Teyke, T. (1996). Consequences of foodattraction conditioning in Helix: A behavioral and electrophysiological study. Journal of Comparative Physiology A, 178, 317-327.

ResCorla, R. A., \& WAGNER, A. R. (1972). A theory of Pavlovian conditioning: Variations in the effectiveness of reinforcement and nonreinforcement. In A. H. Black and W. F. Prokasy (Eds.), Classical conditioning II: Current research and theory (pp. 64-99). New York: Appleton.

Roitblat, H. L. (1987). Introduction to comparative cognition. New York: Freeman.
SAHLEy, C. L., GelPerin, A., \& Rudy, J. W. (1981). An analysis of associative learning in a terrestrial mollusc: I. Higher-order conditioning, blocking and a transient US pre-exposure effect. Journal of Comparative Physiology A, 144, 1-8.

Suzuki, H., Sekiguchi, T., Yamada, A., \& Mizukami, A. (1994). Sensory preconditioning in the terrestrial mollusk, Limax flavus. Zoological Science, 11, 121-125.

TeYKe, T. (1995). Food attraction conditioning in the snail Helix pomatia. Journal of Comparative Physiology A, 177, 409-414.

UNGLESS, M. A. (1998). A Pavlovian analysis of food-attraction conditioning in the snail Helix aspersa. Animal Learning \& Behavior, 26, 15-19.

Ungless, M. A. (2001). Dissociation of food-finding and tentaclelowering, following food-attraction conditioning in the snail, Helix aspersa. Behavioural Processes, 53, 97-101.

WASSERMAN, E. A. (1984). Animal intelligence: Understanding the minds of animals through their behavioural "ambassadors." In H. L. Roitblat, T. G. Bever, \& H. S. Terrace (Eds.), Animal cognition (pp. 45-60). Hillsdale, NJ: Erlbaum.

(Manuscript received April 19, 2005;

revision accepted for publication January 9, 2006.) 